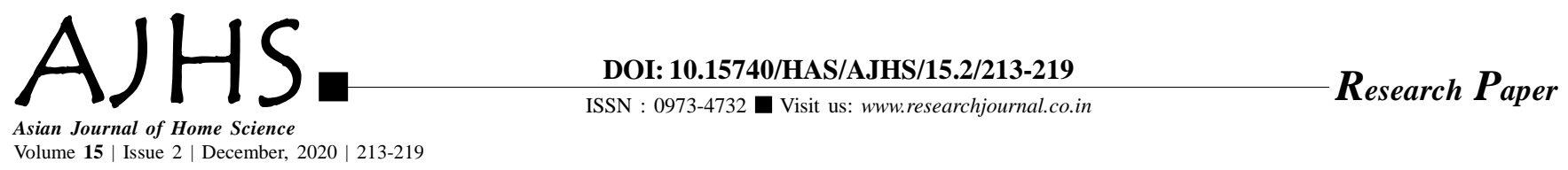

\title{
Reproductive health and wellbeing: complementary to each other
}

\section{Gaytri Tiwari and Sneha Jain}

See end of the paper for authors' affiliations

\section{Sneha Jain}

College of Community and

Applied Sciences, Maharana

Pratap University of Agricultural

Sciences, Udaipur (Rajasthan)

India

Email : snehajain8349@gmail.

com

Received: 03.09.2020; Revised: 12.10.2020; Accepted: 26.10 .2020

ABSTRACT : Generally, women's health receives attention only during pregnancy and the immediate post-partum period. A women's health agenda was first articulated at the Fourth World Conference on Women held in Beijing in 1995. In the resulting Beijing Declaration and Platform for Action, a roadmap for gender equality and women's empowerment was outlined, with a major focus on reproductive and sexual health (SRH) issues, which were the main killers of women then. Present study was carried out in order to find out the reasons of Reproductive Health and wellbeing problem in women children between the age group of 1-6 years and to provide results based remedial solutions and interventions. For this purpose, samples were selected from different villages of nine states in India which includes Assam (Jorhat), Andhra Pradesh (Hyderabad), Haryana (Hissar), Himachal Pradesh (Palampur), Uttar Pradesh (Pantnagar), Rajasthan (Udaipur), Maharashtra (Parbhani), Punjab (Ludhiana), Karnataka(Dharwad) Tamil Nadu (Madurai), Meghalaya (Tura). The wellbeing of women covers five major aspects on physical, social, emotional, spiritual and intellectual. Data analysis was done using frequency, percentage distribution. Results revealed that in the maximum states, the reproductive factor was average only two state were having good reproductive health. Parbhani, and all the states were having average wellbeing of women.

KEY WORDS: Reproductive health, Wellbeing, Women's health

- HOW TO CITE THIS PAPER : Tiwari, Gaytri and Jain, Sneha (2020). Reproductive health and wellbeing: complementary to each other. Asian J. Home Sci., 15 (2) : 213-219, DOI: 10.15740/HAS/AJHS/ 15.2/213-219. Copyright@ 2020: Hind Agri-Horticultural Society. 